\title{
Compassion Protects Mental Health and Social Safeness During the COVID-19 Pandemic Across 21 Countries
}

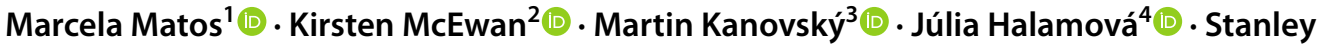

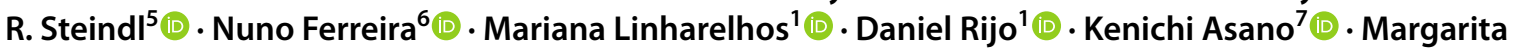

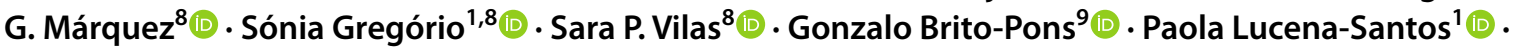

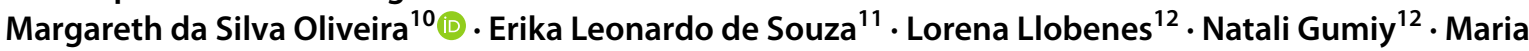 \\ lleana Costa ${ }^{12}$. Noor Habib ${ }^{13}$. Reham Hakem ${ }^{13}$. Hussain Khrad ${ }^{13}$. Ahmad Alzahrani ${ }^{13}$. Simone Cheli ${ }^{14}$.

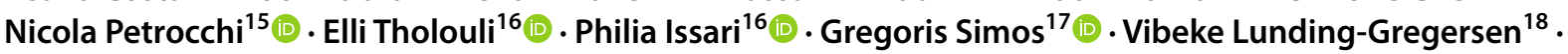 \\ Ask Elklit ${ }^{19}$ - Russell Kolts ${ }^{20}$ (D) Allison C. Kelly ${ }^{21}$ (1) Catherine Bortolon ${ }^{22,23}$ - Pascal Delamillieure ${ }^{24,25}$ (1)

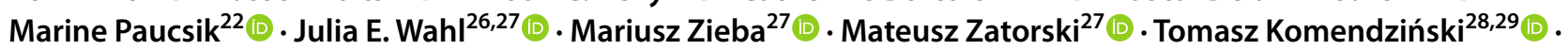

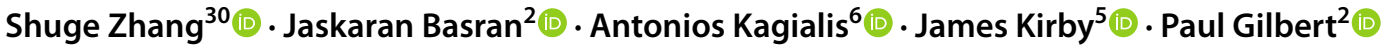

Accepted: 21 December 2021 / Published online: 4 January 2022

(c) The Author(s), under exclusive licence to Springer Science+Business Media, LLC, part of Springer Nature 2022

\begin{abstract}
Objectives The COVID-19 pandemic is having an unprecedented detrimental impact on mental health in people around the world. It is important therefore to explore factors that may buffer or accentuate the risk of mental health problems in this context. Given that compassion has numerous benefits for mental health, emotion regulation, and social relationships, this study examines the buffering effects of different flows of compassion (for self, for others, from others) against the impact of perceived threat of COVID-19 on depression, anxiety, and stress, and social safeness.

Methods The study was conducted in a sample of 4057 adult participants from the general community population, collected across 21 countries from Europe, Middle East, North America, South America, Asia, and Oceania. Participants completed self-report measures of perceived threat of COVID-19, compassion (for self, for others, from others), depression, anxiety, stress, and social safeness.

Results Perceived threat of COVID-19 was associated with higher scores in depression, anxiety, and stress, and lower scores in social safeness. Self-compassion and compassion from others were associated with lower psychological distress and higher social safeness. Compassion for others was associated with lower depressive symptoms. Self-compassion moderated the relationship between perceived threat of COVID-19 on depression, anxiety, and stress, whereas compassion from others moderated the effects of fears of contracting COVID-19 on social safeness. These effects were consistent across all countries. Conclusions Our findings highlight the universal protective role of compassion, in particular self-compassion and compassion from others, in promoting resilience by buffering against the harmful effects of the COVID-19 pandemic on mental health and social safeness.
\end{abstract}

Keywords Compassion $\cdot$ Mental health $\cdot$ Social safeness $\cdot$ COVID-19 $\cdot$ Moderator effect $\cdot$ Multinational study

With nearly 100 million people infected, and over 2 million deaths to date and rising, the COVID-19 pandemic has had a pervasive impact on human society (Worldometer, 2021). In an effort to reduce the spread of the virus and related pressures on healthcare services, many countries around

Marcela Matos

marcela.matos@fpce.uc.pt

Extended author information available on the last page of the article the world have implemented community-level restrictions, such as self-isolation or lockdown procedures, causing significant disruption to key aspects of people's daily life. Furthermore, the highly contagious and invisible nature of the virus has transformed core human behaviors such as social interactions (e.g., shaking hands, hugging) into threatening and potentially deadly experiences. The uncertainty of living with this new pathogen and the ensuing isolation and restrictions to human interaction pose a severe risk to the 
mental health of the general population (Prout et al., 2020; WHO, 2020).

Confrontation with a major threat, such as a pandemic, has a range of negative consequences to mental health and psychosocial well-being. Evidence is already emerging that the implementation of lockdown measures is significantly impacting on mental health, with increasing presentations or exacerbation of stress, depression, anxiety, and sleep problems (Gloster et al., 2020; Lee et al., 2020; Murphy et al., 2020; Serafini et al., 2020; van Tilburg et al., 2020; Wang, Pan, et al., 2020; Wang, Zhang, et al., 2020; Wong et al., 2020). Heightened fear of COVID-19 has been associated with poor mental health indicators, including depression and anxiety (e.g., Ahorsu et al., 2020; Bitan et al., 2020; Fitzpatrick et al., 2020; Kanovsky \& Halamová, 2020). While the unprecedented physical distancing measures have resulted in significant changes to people's social lives and feelings of social safeness, research has documented that social connectedness may buffer against the negative physical and mental health impact of the pandemic, and promote resilience (Nitschke et al., 2020; Palgi et al., 2020; Saltzman et al., 2020). In fact, feeling socially safe is positively related to feeling connected to others and supported in close social relationships, is associated with increased resilience in the face of adversity, and is negatively linked to symptoms of depression and anxiety (Armstrong et al., 2020; Kelly et al., 2012). Social safeness has been proposed as an emotion regulation process in its own right that can be distinguished from positive affect and negative affect, and is a unique predictor of stress (Armstrong et al., 2020), which might act as a buffer against mental health problems. Social safeness is associated with being open and receptive to support and compassion from others (Gilbert, 2009; Kelly \& Dupasquier, 2016; Seppälä et al., 2017), and has been found to be related with decreased traumatic impact of early adverse events and to mediate the link between early emotional trauma and depressive symptoms (Matos et al., 2015). Furthermore, robust evidence has demonstrated that psychological and social factors aggravated by the COVID-19 pandemic (e.g., stress, depression, loneliness) can increase vulnerability for infection after virus exposure (Cohen, 2021) and impair the immune system's response to vaccines (Madison, et al., 2021), and may hence be relevant for susceptibility to COVID-19 and the SARS-CoV-2 vaccine immunization.

Therefore, investigating the protective factors that might mitigate the mental health effects of the COVID-19 pandemic and promote resilience during these adverse times is critical and a research priority for mental health science (Holmes et al., 2020; Vinkers et al., 2020). Compassion plays a pivotal role in emotion regulation, mental states, social relationships, and behavior (Seppälä et al., 2017), and may emerge as a key protective factor against the pervasive impact of the pandemic on mental health. The current study is part of a broader multinational longitudinal study investigating the buffering effects of compassion during the COVID-19 pandemic.

Although compassion can be variously defined (Mascaro et al., 2020), evolutionary-focused models (Gilbert, 2019, 2020) and ancient Buddhist traditions (Dalai Lama, 1995) conceptualize compassion as a prosocial motivation, defined as "the sensitivity to suffering in self and others, with a commitment to try to alleviate and prevent it" (Gilbert, 2014, p. 19). Being sensitive to and engaged with sources of distress rather than avoid, dissociate from, or deny them requires courage, especially in the case of the COVID-19 pandemic. Compassion, evolving from the mammalian care-giving systems, comes with a range of physiological and emotional regulating systems, particularly for down-regulating threat and allowing states of "rest and digest" (Brown \& Brown, 2017; Carter et al., 2017; Mayseless, 2016). Hence, compassion is supported by evolved physiological (e.g., the myelinated vagus nerve, oxytocin) and psychological mechanisms (e.g., social intelligence and competencies) that underpin caring motives and behavior (Carter, 2014; Porges, 2007). Compassion emerges from the combination of an innate mammalian caring motivation and complex human cognitive competencies that have evolved over the last two million years (Dunbar, 2016a, b; Gilbert, 2009, 2019). Compassionate competencies encompass the social intelligences of knowing/mind awareness, empathic awareness, and knowing intentionality that transform basic caring motives into potentials for compassion (Dunbar, 2016a, b; Gilbert, 2019, 2020; Kirby \& Gilbert, 2017).

When individuals are under stress, being cared for and supported by others has powerful physiological effects (Porges, 2007, 2017). Compassion can therefore be seen as a dynamic intra- and interpersonal process that unfolds in a social interactional context: there is the compassion we can express to others, the compassion that can be expressed to us from others, and our ability to be self-compassionate (Gilbert, 2009; Gilbert et al., 2011). These three flows of compassion are highly interactive and can influence each other (Gilbert, 2014; Gilbert et al., 2017), but they can also be independent, in that one may struggle with being compassionate towards oneself but be able to direct compassion to others (Lopez et al., 2018).

Emerging research is suggestive of the benefits of compassion for mental health and emotion regulation (e.g., MacBeth \& Gumley, 2012), physiological health (e.g., Fredrickson et al., 2013; Kim et al., 2020; Klimecki et al., 2014), and interpersonal and social relationships (e.g., Crocker \& Canevello, 2012; Yarnell \& Neff, 2013). In particular, self-compassion has been shown to be a protective factor, increasing resilience to common mental health issues (MacBeth \& Gumley, 2012; Muris \& Petrocchi, 2017) and promoting well-being (Zessin et al., 2015). For example, 
self-compassion has been shown to moderate the relationship between stress, shame, or stigma and psychological distress (Blackie \& Kocovski, 2019; Heath et al., 2018; Luo et al., 2018; Oliveira et al., 2018; Wong et al., 2016). Being compassionate to others has also been associated with reduced negativity (Miller et al., 2015) and stronger social connections (Cozolino, 2007; Crocker \& Canevello, 2012). Moreover, the ability to be open to receiving compassion from others may buffer against depressive symptoms (Hermanto et al., 2016; Steindl et al., 2018). In addition to compassion offering well-being benefits, compassion can also be cultivated and enhanced through interventions such as Compassion-Focused Therapy (CFT; for patients) and Compassionate Mind Training (CMT; for the general public) (Gilbert, 2014, 2020; Gilbert \& Procter, 2006) where it has been shown to diminish mental health issues (e.g., depression, anxiety, stress, self-criticism, shame) (Craig et al., 2020 and Kirby et al., 2017 for reviews; Irons \& HeriotMaitland, 2020; Matos et al, 2017).

In relation to the pandemic, self-compassion has been found to improve life satisfaction and coping ( $\mathrm{Li}$ et al., 2021), cohabitation (Jimenez et al., 2020), and mediated the effect of the perceived COVID-19 threat on death anxiety (Kavakli et al., 2020) and depression, anxiety, and stress (Lau et al., 2020). Going beyond cross-sectional data, in an experimental study, Cheli et al. (2020) found that an online compassion-focused crisis intervention, aimed at promoting compassion for one's own distress and developing one's self-soothing abilities, reduced depression, anxiety, and stress in patients at high risk of psychosis during the pandemic. In support, Schnepper et al. (2020) found that a selfcompassion intervention delivered during the pandemic via Smartphone increased self-compassion, decreased stress, and reduced eating in response to feeling anxious. Hence, existing compassion research in the context of the pandemic has focused primarily on one of the flows of compassion (i.e., self-compassion), even though its moderating role on the association between threat COVID-19, psychological distress, and social safeness remains to be studied. Furthermore, the relationships between the other flows of compassion, specifically compassion for others and receiving compassion from others, and perceived threat of COVID19, psychological distress, and social safeness are yet to be empirically examined.

Additionally, the majority of the aforementioned studies examined a unidimensional construct of self-compassion using the Self-Compassion Scale (Neff, 2003). The proposed study builds on this literature by using a multidimensional measure which distinguishes the three flows of compassion (Compassion Engagement and Action Scales, CEAS; Gilbert et al., 2017). This scale also further distinguishes compassionate engagement (being sensitive and empathic to distress and motivated to engage with it rather than avoid it) from compassionate action (having the wisdom and skills to take the most appropriate action to alleviate distress). This offers an important distinction because being sensitive to distress but not knowing what actions to take can increase rather than decrease distress (Gilbert et al., 2017) and result in burnout (Ricard, 2015).

In previous studies, the flows of compassion for self, for others, and from others (as measured by the CEAS) have demonstrated their distinct qualities. For example, self-compassion (in particular) and receiving compassion from others tend to show the strongest associations and be the greatest predictors of depression, anxiety, stress, and positive affect (Gilbert et al., 2017; Lindsey, 2017; Matos et al., 2017; Steindl et al., 2018). Self-compassion and compassion from others moderate the relationship between negative appraisal of major life events and decreased psychological quality of life (Ferreira et al., 2021). Compassion for others shows weaker associations with distress (Gilbert et al., 2017). The general public report having higher rates of compassion for others, than for themselves or from others (Lindsey, 2017). However, all flows of compassion have been shown to be improved through CMT (Irons \& Heriot-Maitland, 2020; Matos et al., 2017).

The current study aimed to explore the impact of perceived threat of COVID-19 and the three flows of compassion on mental health indicators and social safeness, in a global adult population across 21 countries from Europe, Middle East, North America, South America, Asia, and Oceania. In particular, this study aimed to examine crossnationally whether self-compassion, compassion for others, and receiving compassion from others would moderate the effects of perceived threat of COVID-19 (i.e., fear and likelihood of contracting SARS-CoV-2) on symptoms of depression, anxiety, and stress and feelings of social safeness. Given that previous studies have demonstrated the buffering effect of self-compassion against psychological distress (Blackie \& Kocovski, 2019; Heath et al., 2018; Luo et al., 2018; Oliveira et al., 2018; Wong et al., 2016), we hypothesized that self-compassion would be a protective factor and significant moderator between perceived threat of COVID-19 and depression, anxiety, and stress. It was also hypothesized that compassion from others and to others (although to a lesser degree) would also act as protective factors moderating the impact of fears of COVID-19 on depression, anxiety, and stress. Furthermore, compassion is a predictor of social safeness (Akin \& Akin, 2015; Kelly \& Dupasquier, 2016); hence, it was hypothesized that compassion would act as a protective factor between perceived threat of COVID-19 and social safeness. 


\section{Methods}

\section{Participants}

The research sample was gathered from 23 different countries. We excluded the data from Peru $(N=16)$ and Uruguay $(N=23)$ due to small sample size. The total sample consisted of 21 countries with 4057 participants, mean age $41.45(S D=14.96)$, with $80.8 \%(N=3279)$ women, $18.2 \%$ $(N=739)$ men, $0.4 \%(N=15)$ other, and $0.6 \%(N=24)$ preferred not to respond. For demographic details per country, see Table 1 .

\section{Procedures}

This study is part of a broader longitudinal multinational study on compassion, social connectedness, and trauma resilience during the COVID-19 pandemic. The study was approved by the Ethics Committee of the Faculty of Psychology and Educational Sciences of the University of Coimbra (UC; CEDI22.04.2020) and was conducted in compliance with the 1964 Helsinki Declaration and its later amendments. When necessary, local national ethical approval was also obtained. The current analysis used cross-sectional data collected between mid-April 2020 and mid-May 2020, across 23 countries from Europe (UK,
Portugal, Spain, Italy, France, Greece, Cyprus, Poland, Slovakia, Denmark), North America (USA, Canada), South America (Brazil, Argentina, Chile, Colombia, Mexico, Peru, Uruguay), Asia (China, Japan), Oceania (Australia), and Middle East (Saudi Arabia).

An online survey, combining existing and novel measures, was created by the research team in English and translated to 11 other languages using forward/backward procedures. In instances where a self-report questionnaire had already been validated for a particular language/country that version was selected. The surveys were hosted at the University of Coimbra institutional account in the online platform https://www.limesurvey.org/pt/, and a website was created to support the dissemination of the study across countries (https://www.fpce.uc.pt/covid19stu $\mathrm{dy} /$ ). The study was disseminated through social and traditional media platforms and institutional/professional emailing lists in each country, using snowball sampling. In addition, Facebook ads were used to promote participation among the general population in some countries. Before the completion of the survey, participants were informed about the aims of the study, procedures, and the voluntary and anonymous nature of participation. Confidentiality of the collected data was assured, and written informed consent was obtained before the completion of the study protocol. The survey was self-paced and about 25 min long. There was no payment for completing the survey.
Table 1 Research samples with sociodemographic information

\begin{tabular}{lllllllr}
\hline Country & Size & Male & Female & Other & $\begin{array}{l}\text { I prefer not to } \\
\text { respond }\end{array}$ & Mean age & SD age \\
\hline Argentina & 257 & 33 & 223 & 0 & 1 & 46.48 & 12.151 \\
Australia & 109 & 16 & 92 & 1 & 0 & 49.31 & 14.594 \\
Brazil & 299 & 31 & 267 & 1 & 0 & 42.79 & 12.534 \\
Canada & 115 & 24 & 89 & 0 & 2 & 48.41 & 18.886 \\
China & 77 & 28 & 48 & 0 & 1 & 39.95 & 15.024 \\
Chile & 282 & 32 & 250 & 0 & 0 & 45.91 & 11.498 \\
Colombia & 50 & 11 & 39 & 0 & 0 & 46.30 & 13.132 \\
Cyprus & 38 & 3 & 35 & 0 & 0 & 31.55 & 11.608 \\
Denmark & 141 & 23 & 118 & 0 & 0 & 48.82 & 11.869 \\
France & 115 & 21 & 94 & 0 & 0 & 46.71 & 16.337 \\
Great Britain & 268 & 30 & 236 & 1 & 1 & 46.62 & 13.808 \\
Greece & 145 & 15 & 130 & 0 & 0 & 35.60 & 13.532 \\
Italy & 160 & 40 & 120 & 0 & 0 & 41.47 & 12.988 \\
Japan & 522 & 183 & 326 & 4 & 9 & 29.56 & 13.421 \\
Mexico & 181 & 35 & 144 & 0 & 2 & 46.89 & 12.125 \\
Poland & 82 & 12 & 69 & 0 & 1 & 43.94 & 12.471 \\
Portugal & 394 & 82 & 310 & 1 & 1 & 42.16 & 12.838 \\
Saudi Arabia & 256 & 24 & 226 & 0 & 6 & 23.89 & 8.008 \\
Slovakia & 46 & 6 & 40 & 0 & 0 & 34.89 & 10.067 \\
Spain & 392 & 78 & 314 & 0 & 0 & 46.81 & 12.478 \\
USA & 128 & 12 & 109 & 7 & 0 & 48.18 & 14.817 \\
\hline & & & & & & &
\end{tabular}




\section{Measures}

The online survey collected sociodemographic information (nationality, country of residence, age, gender) and administered self-report instruments assessing perceived threat of COVID-19, compassion (for self, for others, from others), mental health (depression, anxiety, and stress), and social safeness.

The Perceived Coronavirus Risk Scale (PCRS; Kanovský \& Halamová, 2020, adapted from Napper et al., 2012) is an 8-item self-report questionnaire that assesses participants' fear of getting infected with SARS-CoV-2 in two dimensions: Fear of Contraction (affective aspect) and Likelihood of Contraction (cognitive aspect). Participants are asked to rate on a five-point Likert scale how much they agree with each sentence from 1 (strongly disagree) to 5 (strongly agree). It has one reversed item. Higher scores represent a higher perceived threat of COVID-19. In the original study, Kanovsky and Halamová (2020) reported internal consistency to be acceptable (Fear of Contraction $\alpha=0.72$; Likelihood of Contraction $\alpha=0.71$ ). In the present study, internal consistency was acceptable (Fear of Contraction $\alpha=0.70$; Likelihood of Contraction $\alpha=0.70$ ). Omega coefficient for the PTCS was 0.83, and Omega hierarchical 0.64. In our sample, the CFA results revealed that the PTCS model had a good fit to the data: $\chi^{2}(519.23)$, df $13, \mathrm{CFI}=0.913$, $\mathrm{TLI}=0.880, \mathrm{RMSEA}=0.078(90 \%$ CI 0.071-0.085), SRMR 0.050 .

Compassionate Engagement and Action Scales (CEAS; Gilbert et al., 2017) includes three scales that assess the three flows of compassion: self-compassion (CEAS self-compassion), compassion for others (CEAS for others), and compassion received from others (CEAS from others), with 13 items each. Each scale measures different elements of compassion Engagement (6 items and 2 filler items) and Action (4 items and 1 filler item). Participants are asked to rate each item on a ten-point Likert scale, based on how frequently it occurs, from 1 (never) to 10 (always). Each scale can be analyzed in terms of the Engagement and Action components separately or as a single factor. Here, we use each of the three flows of compassion as single factor scales. In the original study, the CEAS showed good internal consistencies and temporal reliability (Gilbert et al., 2017). In the present study, internal consistency ranged between good and excellent: CEAS selfcompassion Engagement $\alpha=0.74 /$ Action $\alpha=0.89$; CEAS for others Engagement $\alpha=0.81 /$ Action $\alpha=0.88$; CEAS from others Engagement $\alpha=0.91 /$ Action $\alpha=0.93$. Omega coefficient for CEAS self-compassion was 0.90, and Omega hierarchical 0.70. Omega coefficient for CEAS for others was 0.92, and Omega hierarchical 0.78. Omega coefficient for CEAS from others was 0.96, and Omega hierarchical 0.88. Results from the CFA showed that, in this study, the CEAS self-compassion model had a good fit to the data: $\chi^{2}(957.55)$, df $34, \mathrm{CFI}=0.918, \mathrm{TLI}=0.892, \mathrm{RMSEA}=0.072(90 \% \mathrm{CI}$ 0.068-0.075), SRMR 0.068; the CEAS for others model had a good fit to the data: $\chi^{2}(516.15)$, df $34, \mathrm{CFI}=0.956$, $\mathrm{TLI}=0.942$, RMSEA $=0.059(90 \%$ CI $0.056-0.063)$, SRMR 0.037; and the CEAS from others model had a good fit with the data: $\chi^{2}(559.41)$, df $34, \mathrm{CFI}=0.972$, TLI $=0.962$, RMSEA $=0.062$ (90\% CI 0.058-0.065), SRMR 0.025.

Depression, Anxiety and Stress Scales (DASS-21; Lovibond \& Lovibond, 1995) is a 21-item self-report instrument that measures three mood states: depression, anxiety, and stress, with seven items each. Participants are asked to rate on a four-point Likert scale how often items applied to them over the past week from 0 (did not apply to me at all) to 3 (applied to me very much, or most of the time). Higher scores represent higher severity of symptoms. Lovibond and Lovibond (1995) found the subscales internal consistency to range between excellent and good (Depression $\alpha=0.91$; Anxiety $\alpha=0.84$; Stress $\alpha=0.90$ ). In the present study, internal consistency also ranged from good to excellent (Depression $\alpha=0.91$, Anxiety $\alpha=0.87$, Stress $\alpha=0.88$ ). Omega coefficient for DASS was 0.96 , and Omega hierarchical 0.82 . CFA results revealed that the DASS model had a good fit to the data: $\chi^{2}(2018.30)$, df $186, \mathrm{CFI}=0.943$, TLI $=0.936$, RMSEA $=0.061$ (90\% CI 0.058-0.063), SRMR 0.037.

Social Safeness and Pleasure Scale (SSPS; Gilbert et al., 2008) is an 11-item self-report measure that assesses the extent to which people usually experience their social world as safe, warm, and soothing and how connected they feel to others. Participants are asked to rate on a five-point Likert scale how often they feel as described in each sentence from 1 (almost never) to 5 (almost all the time). Higher scores represent higher perceived social safeness and connectedness to others. In the original study, internal consistency was excellent $(\alpha=0.92)$. In the present study, internal consistency is excellent $(\alpha=0.94)$. Omega coefficient for SSPS was 0.95, and Omega hierarchical 0.86. Results from the CFA revealed that the SSPS model had a good fit to the data: $\chi^{2}(1516.48)$, df $44, \mathrm{CFI}=0.931$, TLI $=0.913, \mathrm{RMSEA}=0.071(90 \% \mathrm{CI}$ 0.068-0.084), SRMR 0.039.

\section{Data Analyses}

The data includes multiple dependent variables; for example, the DASS-21 scale has three subscales (depression, anxiety, and stress). Therefore, a multivariate multilevel model was chosen because it enables the performance of a single test of the joint effects of our independent variables on several dependent variables (Hox et al., 2017; Snijders \& Bosker, 2012). Each of the models had three levels: measurements of dimensions of the DASS-21 were the level 1 units, the respondents were the level 2 units, and the countries were the level 3 units. 
The statistical procedure for the three-dimensional DASS-21 was as follows: (1) fitting six multilevel multivariate models, each with three dependent variables (depression, anxiety, stress): (a) PCRS fear of contraction as the predictor (independent variable, IV), CEAS self-compassion as the predictor (IV), and their interaction (CEAS self-compassion being the moderator); (b) PCRS likelihood of contraction as the predictor (IV), the CEAS self-compassion as the predictor (IV), and their interaction (CEAS self-compassion being the moderator); (c) PCRS fear of contraction as the predictor (IV), CEAS compassion for others as the predictor (IV), and their interaction (CEAS compassion for others being the moderator); (d) PCRS likelihood of contraction as the predictor (IV), CEAS compassion for others as the predictor (IV), and their interaction (CEAS compassion for others being the moderator); (e) PCRS fear of contraction as the predictor (IV), CEAS compassion from others as the predictor (IV), and their interaction (CEAS compassion from others being the moderator); (f) PCRS likelihood of contraction as the predictor (IV), CEAS compassion from others as the predictor (IV), and their interaction (CEAS compassion from others being the moderator); (2) for each model, we tested the fit of three nested models with the data by two likelihood-ratio tests and information criteria AIC (Akaike information criterion) and BIC (Bayes Schwarz information criterion): (a) the first model was the multilevel model without taking into account three dimensions of the DASS-21, and having two main predictors (IVs) without the moderation; (b) the second model was the multivariate multilevel model taking into account three dimensions of the DASS-21, and having two main predictors (IVs) without the moderation; and finally (c) the third model was the multivariate multilevel model taking into account three dimensions of the DASS-21, and having two predictors (IVs) with the moderation. Our hypothesis in its strict form could have been retained if and only if (a) the second model had a better fit than the first one (taking into account the dimensions of the DASS-21 was justified-respondents provided different answers in DASS-21 different dimensions; otherwise, the use of the multivariate model would not be warranted); (b) the third model had the better fit than the second one-adding moderation should improve the fit. If not, only main effects (and no moderation) could have had an impact; (3) if the third model had the best fit, we would report and interpret its coefficient ( $p$-values would be corrected by Bonferroni procedure to account for multiple testing); (4) otherwise, we would report coefficients of any model with the best fit; we also provided the graphical representations of effects. Since the SSPS is a unidimensional scale, the univariate multilevel model was sufficient. Two models were fitted: (a) PCRS fear of contraction as the predictor (IV), and (b) PCRS likelihood of contraction as the predictor (IV); and both models contained the same set of three moderators: compassion for self, compassion for others, and compassion from others.

For our multilevel model, sample size was calculated in $\mathrm{R}$ package simr (Green \& MacLeod, 2016). For 21 countries, the overall sample size should be over 3000 participants, and sample size of each country should not be under 30 participants. The statistical power was set for $80 \%$. To further assess the psychometric properties of the self-report scales used in the current study, Omega coefficients were computed and confirmatory factor analyses (CFA) with robust maximum likelihood estimator and Yuan-Bentler correction were conducted.

For statistical analyses, we used the $\mathrm{R}$ program version 4.0.3 (R Core Team, 2020), "Ime4" package (Bates et al., 2015). The effects were displayed through "sjPlot" package (Lüdecke, 2018). As fixed effects, we entered the mean-centered PCRS subscale scores in an interaction with the meancentered CEAS scales scores for each dimension of DASS-21, and for the SSPS. As random effects, we used intercepts for participants and countries for each dimension of DASS-21 and intercept for countries for the SSPS. For mean centering, we used "questionr" package (Barnier et al., 2017).

The $\mathrm{R}$ code syntax for the model is included in Supplementary Online Material 1. $R^{2}$ ('variance explained') statistics were used to measure the effect size of the model. However, there is no consensus as to the most appropriate definition of $R^{2}$ statistics in relation to mixed-effect models (Edwards et al., 2008; Jaeger et al., 2016; LaHuis et al., 2014; Nakagawa \& Schielzeth, 2013). Even though several methods for estimating the coefficient of determination $\left(R^{2}\right)$ for mixed-effect models are accessible, the estimation of $R^{2}$ marginal and $R^{2}$ conditional in "MuMIn" package (Barton, 2015) was performed. The marginal $R^{2}$ is the proportion of variability explained by the fixed effects/independent variable; the conditional $R^{2}$ is the proportion of variability explained by both fixed and random effects (differences between respondents and differences between countries).

\section{Results}

Descriptive statistics of the main variables under study and Spearman correlations between the variables are reported in Table 2. Correlation results revealed that the perceived threat of COVID-19 dimensions (fear and likelihood of contraction) were positively associated with depression, anxiety, and stress, negatively linked to social safeness. Self-compassion and compassion from others were negatively correlated with depression, anxiety, and stress, and positively associated with social safeness. Compassion for others was negatively correlated with depression and positively with social safeness.

In Table 3, the likelihood-ratio tests and information criteria AIC and BIC are presented. It is evident from 
Table 2 Descriptive statistics (means and standard deviations) and Spearman's rho correlations of the study variables $(N=4057)$

\begin{tabular}{|c|c|c|c|c|c|c|c|c|c|c|}
\hline \multirow[t]{2}{*}{ Variables } & \multirow[t]{2}{*}{$M$} & \multirow[t]{2}{*}{$S D$} & \multirow[b]{2}{*}{$\begin{array}{l}\text { CEAS } \\
\text { self-compassion }\end{array}$} & \multicolumn{7}{|c|}{ Correlations } \\
\hline & & & & $\begin{array}{l}\text { CEAS } \\
\text { for others }\end{array}$ & $\begin{array}{l}\text { CEAS } \\
\text { from others }\end{array}$ & PCRS fear & PCRS likelihood & $\begin{array}{l}\text { DASS } \\
\text { depression }\end{array}$ & $\begin{array}{l}\text { DASS } \\
\text { anxiety }\end{array}$ & $\begin{array}{l}\text { DASS } \\
\text { stress }\end{array}$ \\
\hline CEAS self-compassion & 69.64 & 13.98 & & & & & & & & \\
\hline CEAS for others & 77.02 & 13.10 & $.45^{* *}$ & & & & & & & \\
\hline CEAS from others & 61.05 & 18.10 & $.31 * *$ & $.31 * *$ & & & & & & \\
\hline PCRS fear & 8.45 & 2.94 & $-.06^{* *}$ & $.05 * *$ & $-.03 *$ & & & & & \\
\hline PCRS likelihood & 12.97 & 3.20 & $-.06^{* *}$ & $.04 * *$ & -.02 & $.45^{* *}$ & & & & \\
\hline DASS depression & 4.76 & 4.86 & $-.38 * *$ & $-.10 * *$ & $-.25^{* *}$ & $.20 * *$ & $.11 * *$ & & & \\
\hline DASS anxiety & 3.06 & 4.02 & $-.24 * *$ & -.01 & $-.15^{* *}$ & $.32 * *$ & $.15^{* *}$ & $.61 * *$ & & \\
\hline DASS stress & 6.16 & 4.75 & $-.28 * *$ & -.01 & $-.16^{* *}$ & $.29 * *$ & $.20^{* *}$ & $.71 * *$ & $.70 * *$ & \\
\hline SPSS & 40.58 & 9.95 & $.43 * *$ & $.30 * *$ & $.54 * *$ & $-.05^{* *}$ & $-.04 * *$ & NA & NA & NA \\
\hline
\end{tabular}

CEAS Compassionate Engagement and Action Scales; PCRS Perceived Coronavirus Risk Scale (fears of contraction; likelihood of contraction); DASS Depression Anxiety and Stress Scales; SPSS Social Safeness and Pleasure Scale. ${ }^{* *} p<.001,{ }^{*} p<.050$

Table 3 that all multivariate models (b-models) consistently had a better fit than models that did not take dimensionality into account. However, only models with selfcompassion as moderator (1c and $2 \mathrm{c}$ ) had a better fit than models without moderation.

\section{Compassion for Self}

Table 4 presents coefficients of best-fitting models for selfcompassion (1c, 2c). The main effects of fear of contraction on depression, anxiety, and stress were all significant (and positive). The main effects of self-compassion on all three dimensions of the DASS-21 were all significant as well (but negative). Interaction effects were significant in all three dimensions of the DASS-21 indicating that self-compassion significantly moderates the impact of the fear of contraction on depression, anxiety, and stress, across all countries. The variability among respondents was lowest in anxiety, and so was the variability among countries, which was in general larger than the individual variability, especially in depression and stress.

Table 3 The likelihood-ratio tests and information criteria AIC and BIC for the different models

\begin{tabular}{|c|c|c|c|c|c|c|c|}
\hline Model & $\begin{array}{l}\text { Predictor } \\
\text { (independent variable) }\end{array}$ & Moderator & Deviance & $\chi^{2}(\mathrm{df})$ & $p$-value & AIC & $\mathrm{BIC}$ \\
\hline $1 \mathrm{a}$ & & & 66,772 & & & 66,782 & 66,819 \\
\hline $1 b$ & Fear of contraction & Compassion for self & 63,099 & $3673(14)$ & $<.001$ & 63,137 & 63,278 \\
\hline $1 c$ & & & 63,051 & $48(3)$ & $<.001$ & 63,095 & 63,258 \\
\hline $2 \mathrm{a}$ & & & 66,955 & & & 66,965 & 67,002 \\
\hline $2 b$ & Likelihood of contraction & Compassion for self & 63,333 & $3623(14)$ & $<.001$ & 63,371 & 63,517 \\
\hline $2 c$ & & & 63,310 & $23(3)$ & $<.001$ & 63,354 & 63,512 \\
\hline $3 a$ & & & 67,251 & & & 67,261 & 67,298 \\
\hline $3 \mathbf{b}$ & Fear of contraction & Compassion for others & 63,686 & 3565 (14) & $<.001$ & 63,724 & 63,864 \\
\hline $3 \mathrm{c}$ & & & 63,685 & $0.89(3)$ & .823 & 63,729 & 63,892 \\
\hline $4 a$ & & & 67,443 & & & 67,453 & 67,490 \\
\hline $4 b$ & Likelihood of contraction & Compassion for others & 63,931 & $3512(14)$ & $<.001$ & 63,969 & 64,110 \\
\hline $4 c$ & & & 63,930 & $0.55(3)$ & .908 & 63,975 & 64,138 \\
\hline $5 \mathrm{a}$ & & & 67,087 & & & 67,097 & 67,134 \\
\hline $5 \mathbf{b}$ & Fear of contraction & Compassion from others & 63,455 & $3632(14)$ & $<.001$ & 63,493 & 63,634 \\
\hline $5 c$ & & & 63,454 & $1.82(3)$ & 610 & 63,498 & 63,660 \\
\hline $6 a$ & & & 67,284 & & & 67,294 & 67,331 \\
\hline $6 \mathbf{b}$ & Likelihood of contraction & Compassion from others & 63,702 & $3582(14)$ & $<.001$ & 63,740 & 63,881 \\
\hline $6 c$ & & & 63,696 & $6.32(3)$ & .097 & 63,740 & 63,903 \\
\hline
\end{tabular}


Table 4 Coefficients of the best-fitting models for selfcompassion

\begin{tabular}{|c|c|c|c|}
\hline \multicolumn{4}{|l|}{ Fixed effects } \\
\hline Model 1c & Main effects & & Moderation \\
\hline$\beta[95 \% \mathrm{CI}]$ & Fear of contraction & Compassion for self & Fear:for self \\
\hline Anxiety & $0.37[0.33: 0.41] * * *$ & $-0.06[-0.07:-0.05]^{* * *}$ & $-0.009[-0.011:-0.006]^{* * *}$ \\
\hline Depression & $0.27[0.22: 0.31]^{* * *}$ & $-0.13[-0.14:-0.12]^{* * *}$ & $-0.005[-0.008:-0.002]^{* * *}$ \\
\hline Stress & $0.40[0.35: 0.45]^{* * *}$ & $-0.09[-0.10:-0.08]^{* * *}$ & $-0.007[-0.010:-0.004]^{* * *}$ \\
\hline \multicolumn{4}{|c|}{ Random effects } \\
\hline$\sigma^{2}$ & Respondents & Countries & \\
\hline Anxiety & 8.62 & 9.75 & residual $=3.84$ \\
\hline Depression & 14.08 & 22.86 & $\mathrm{R}^{2}($ marginal $)=.073$ \\
\hline Stress & 14.28 & 37.92 & $\mathrm{R}^{2}($ conditional $)=.898$ \\
\hline Model 2c & Main effects & & Moderation \\
\hline$\beta[95 \% \mathbf{C I}]$ & Likelihood of contraction & Compassion for self & Likelihood:for self \\
\hline Anxiety & $0.19[0.16: 0.23]^{* * *}$ & $-0.07[-0.08:-0.06]^{* * *}$ & $-0.006[-0.008:-0.003]^{* * *}$ \\
\hline Depression & $0.16[0.11: 0.20]^{* * *}$ & $-0.13[-0.14:-0.12]^{* * *}$ & $-0.004 \mathrm{~ns}$ \\
\hline Stress & $0.26[0.22: 0.31] * * *$ & $-0.09[-0.10:-0.08]^{* * *}$ & $-0.005[-0.008:-0.002]^{* *}$ \\
\hline \multicolumn{4}{|c|}{ Random effects } \\
\hline$\sigma^{2}$ & Respondents & Countries & \\
\hline Anxiety & 8.62 & 9.75 & Residual $=3.60$ \\
\hline Depression & 14.08 & 22.86 & $R^{2}($ marginal $)=.057$ \\
\hline Stress & 14.28 & 37.92 & $R^{2}($ conditional $)=.894$ \\
\hline
\end{tabular}

Figure 1 displays marginal effects of moderation of selfcompassion in the case of fear of contraction: all slopes for highly self-compassionate subjects (green) were less steep than other slopes; therefore, self-compassion buffers against the impact of fear of contraction on depression, anxiety, and stress, with the largest effect of moderation (the least parallel lines) being for anxiety, followed by stress and depression. A similar pattern was present when the likelihood of contraction was the predictor (IV), but the main effects were weaker. Self-compassion significantly moderated the impact of the likelihood of contraction on anxiety and stress (across all countries), but not depression.

\section{Compassion for Others}

Table 5 presents coefficients of best-fitting models for compassion for others $(3 b, 4 b)$. The main effects of fear of contraction on depression, anxiety, and stress were again all significant (and positive), but the main effect of compassion for others was significant (and negative) only in depression. Interaction effects were not tested, since the model with them did not significantly improve the fit with the data (see Table 3 ). The variability among respondents was again lowest in anxiety, and so was the variability among countries, which was larger than the individual variability, in both depression and stress. An identical pattern was discernible for the likelihood of contraction.

\section{Compassion from Others}

Table 6 presents the coefficients of best-fitting models for compassion from others $(5 b, 6 b)$. The main effects of fear of contraction and likelihood of contraction on depression, anxiety, and stress were all significant (and positive), and so were all main effects of compassion from others (but negative). Interaction effects were not tested, since the model with them did not significantly improve the fit with the data (see Table 3). The variability among respondents was lowest in anxiety, and so was the variability among countries, which was larger than the individual variability, both in depression and stress. Again, the likelihood of contraction as the predictor (IV) showed a similar pattern of results, and thus the same conclusion can be reached.

\section{Social Safeness}

Table 7 presents the coefficients of two models with the SSPS social safeness. The main effect of fear of contraction on SSPS was significant (and negative), and the main effects for self-compassion and compassion from others were significant (and positive). The main effect for compassion for others was found to be non-significant. Only compassion from others significantly moderated the effect of fear of contraction on the SSPS across all countries. While the same pattern of main effects can be seen when the likelihood of contraction is the predictor (IV), no moderation effect was found. 


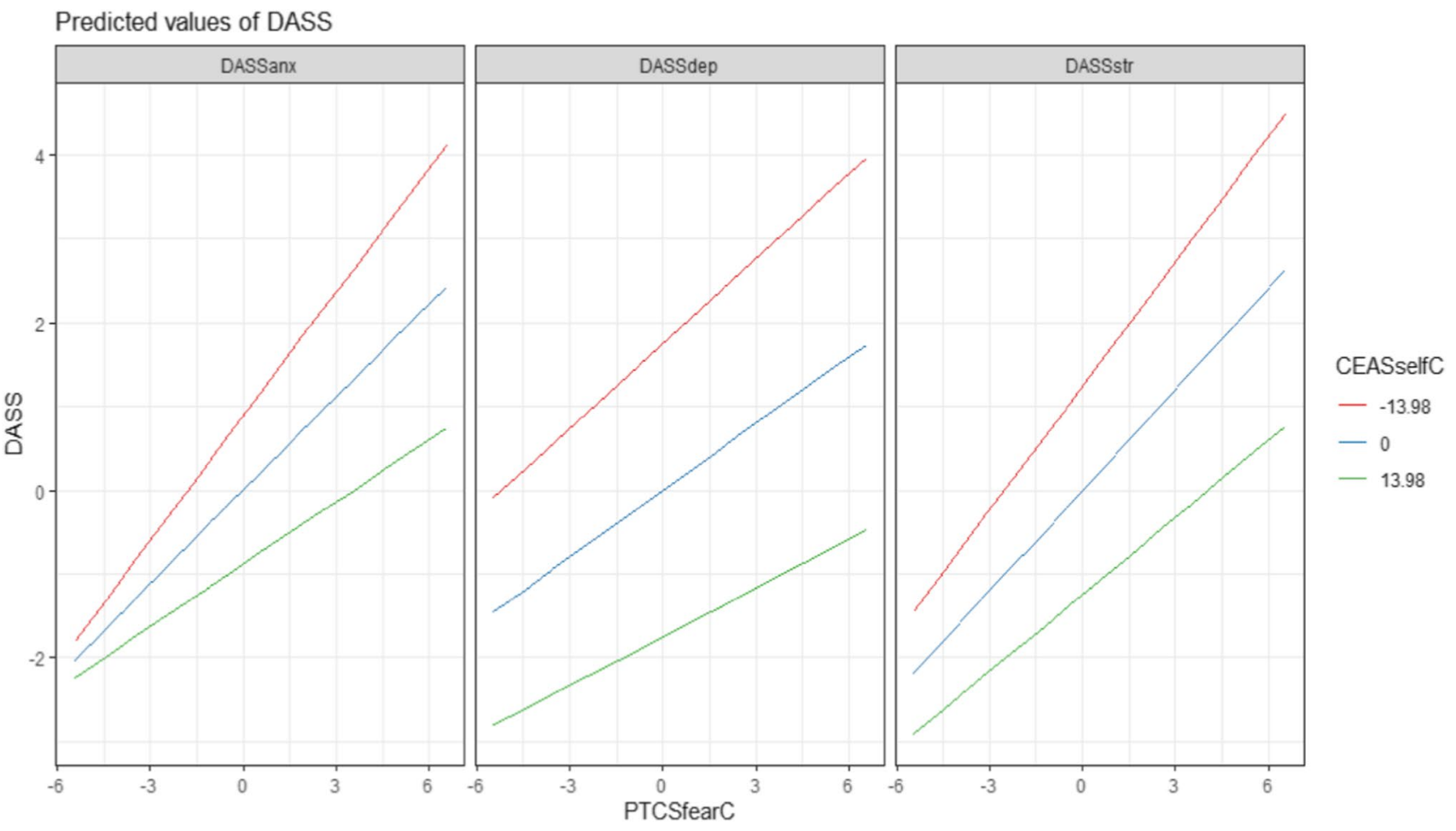

Fig. 1 Marginal effects of moderation of self-compassion (CEASselfC) on the impact of fear of contraction of COVID-19 (PTCSfearC) on depression, anxiety, and stress (DASS)

Table 5 Coefficients of the bestfitting models for compassion for others

\section{Fixed effects}

\section{Model 3b}

$\beta[95 \% \mathrm{CI}]$

Anxiety

Depression

Stress

Random effects

$\sigma^{2}$

Anxiety

Depression

Stress

Model 4b

$\beta[95 \% \mathrm{CI}]$

Anxiety

Depression

Stress

Random effects

$\sigma^{2}$

Anxiety

Depression

Stress

\section{Main effects}

Fear of contraction

$0.40[0.36: 0.44] * * *$

$0.32[0.27: 0.37]^{* * *}$

0.44 [0.39:0.49]***

\section{Respondents}

8.73

16.22

15.08

Main effects

Likelihood of contraction

0.21 [0.17:0.25]***

$0.19[0.15: 0.24]^{* * *}$

0.29 [0.24:0.33]***

\section{Respondents}

9.61

16.71

15.88
Compassion for others

$0.002 \mathrm{~ns}$

$-0.02[-0.03:-0.01]^{* *}$

$-0.002 \mathrm{~ns}$

\section{Countries}

10.10

23.52

38.40

Compassion for others $0.001 \mathrm{~ns}$

$-0.02[-0.03:-0.01]^{* *}$

$-0.003 \mathrm{~ns}$

\section{Countries}

10.38

23.60

38.62

\section{Moderation}

Fear:for others

N/A

N/A

N/A

Residual $=4.60$

$R^{2}($ marginal $)=.030$

$R^{2}$ (conditional $)=.896$

Moderation

Likelihood:for others

N/A

N/A

N/A

Residual $=4.57$

$R^{2}($ marginal $)=.013$

$R^{2}($ conditional $)=.897$ 
Table 6 Coefficients of bestfitting models for compassion from others
Table 7 Coefficients of the two models related to social safeness (SPSS)
Fixed effects

Model 5b

Main effects

$\beta[95 \% \mathrm{CI}]$

Fear of contraction

Anxiety

$0.39[0.35: 0.43]^{* * *}$

Depression

$0.30[0.25: 0.35]^{* * *}$

Stress

$0.43[0.38: 0.48]^{* * *}$

Random effects

$\sigma^{2}$

Anxiety

Respondents

Depression

8.61

Stress

15.13

14.72

Model 6b

Main effects

$\beta[95 \% \mathrm{CI}]$

Likelihood of contraction

Anxiety

Depression

$0.20[0.17: 0.25]^{* * * *}$

Stress

0.18 [0.15:0.24]***

Random effects

$\sigma$

Anxiety

Respondents

Depression

9.44

Stress

15.58

15.48
Compassion from others

$-0.03[-0.04:-0.02]^{* * *}$

$-0.06[-0.07:-0.05]^{* * *}$

$-0.04[-0.05:-0.03]^{* * *}$

Countries

9.88

23.04

38.13

Compassion from others

-0.03 [-0.04: -0.02$] * * *$

$-0.06[-0.07:-0.05]^{* * *}$

$-0.04[-0.05:-0.03]^{* * *}$

Countries

10.12

23.06

38.29
Moderation

Fear:from others

N/A

N/A

N/A

Residual $=4.51$

$R^{2}$ (marginal $)=.046$

$R^{2}$ (conditional $)=.900$

Moderation

Likelihood:from others

N/A

N/A

N/A

Residual $=4.51$

$R^{2}$ (marginal $)=.028$

$R^{2}($ conditional $)=.899$
Model $1 \quad$ Fixed effects

Main effects

$\beta[95 \% \mathrm{CI}]$

Intercept

40.71 [39.81:41.61] $]^{* * *}$

Fear of contraction

-0.15 [-0.24:.0.07]***

Random effects

$\sigma^{2}$

Countries

4.00

Model 2

Fixed effects

Main effects

$\beta[95 \% \mathrm{CI}]$

Intercept

40.71 [39.81:41.61]***

Likelihood of contraction

-0.14 [-0.24:.0.07]***

Random effects

$\sigma^{2} \quad$ Countries

Compassion from self

0.19 [0.17:0.21]***

Compassion for others

$0.01 \mathrm{~ns}$

Compassion from others

0.25 [0.23:0.26]***

Residual

56.59

Compassion from self

0.19 [0.17:0.21]***

Compassion for others

$0.01 \mathrm{~ns}$

Compassion from others $0.25[0.23: 0.26]^{* * *}$

Residual

56.66

\section{Moderation}

Fear:for self

$-0.001 \mathrm{~ns}$

Fear:for others

$0.003 \mathrm{~ns}$

Fear:from others 0.005 [0.004:0.006]*

$R^{2}($ marginal $)=.37$

$R^{2}($ conditional $)=.41$

\section{Moderation}

Likelihood:for self

N/A

Likelihood:for others

N/A

Likelihood:from others N/A

$R^{2}($ marginal $)=.37$

$R^{2}($ conditional $)=.41$

\section{Discussion}


The aims of this study were to assess how different flows of compassion (for self, to others, from others) act as a protective factor against perceived threat of COVID-19 on mental health and social safeness. In line with our hypothesis, perceived threat of COVID-19 predicted higher scores in depression, anxiety, and stress. So, being afraid of contracting the virus was linked to increased psychological distress. This is consistent with previous studies which have revealed that fears of COVID-19 are associated to mental health difficulties (e.g., Ahorsu et al., 2020; Bitan et al., 2020; Fitzpatrick et al., 2020; Kanovsky \& Halamová, 2020; Matos et al., 2021). Given that previous studies have demonstrated the buffering effect of self-compassion against psychological distress (Blackie \& Kocovski, 2019; Heath et al., 2018; Luo et al., 2018; Oliveira et al., 2018; Wong et al., 2016), including in the context of COVID-19 (Jimenez et al., 2020; Kavakli et al., 2020; Lau et al., 2020; Li et al., 2021), it was hypothesized that self-compassion would be a protective factor and significant moderator between the perceived threat of COVID-19 (i.e., fear and likelihood of contraction) and depression, anxiety, and stress. This hypothesis was supported and self-compassion was found to significantly predict lower psychological distress in the context of the COVID-19 pandemic. This means that individuals who were able to be compassionate towards themselves presented fewer symptoms of depression, anxiety, and stress. Importantly, self-compassion moderated the impact of fear of contracting COVID-19 on depression, anxiety, and stress, acting as a protective factor. Furthermore, self-compassion buffered the effects of the perceived likelihood of contraction on anxiety and stress. This moderator effect of self-compassion was particularly strong between perceived threat of COVID-19 and anxiety. This means that, in those individuals who were able to be more compassionate towards themselves and use self-compassion as a way of coping with this threatening pandemic context, the impact of fears of COVID-19 on symptoms of anxiety, depression, and stress was less severe. In the early stages of the pandemic, these individuals were hence protected against the harmful effects of the perceived threat of COVID-19 on their mental health. This moderator effect was consistent across all 21 countries and was not affected by differences in questionnaire responses between countries.

Unique to this study was the multidimensional measurement of compassion which considers the flows of selfcompassion, and compassion for others and from others. It was hypothesized that the flows of compassion for others and from others (although to a lesser degree than selfcompassion) would also act as protective factors moderating the impact of perceived threat of COVID-19 on depression, anxiety, and stress. These hypotheses were not supported. While compassion for others was significantly linked to lower depressive symptoms and compassion from others was significantly associated with depression, anxiety, and stress across all countries, these flows of compassion were not significant moderators and therefore cannot be said to be protective factors against the impact of perceived threat of COVID-19 on developing or exacerbating symptoms of depression, anxiety, or stress. Previous studies using the three flows of compassion have found that compassion for others has the weakest association with other psychological distress variables (e.g., Kirby et al., 2019). The data were collected during the early stages of the pandemic and therefore fears of contracting and spreading COVID-19 and the lockdown measures implemented may have resulted in lower availability of social contact and therefore it is not surprising that compassion for others and receiving compassion from others did not emerge as significant protective factors against perceived threat of COVID-19 on mental health indicators. Interestingly, in a related study where we examined the moderator effects of fears of compassion on the context of the pandemic, the three flows of fears of compassion magnified the impact of perceived threat of COVID-19 on mental health indicators (Matos et al., 2021). A possible explanation is that, if the threat system is activated (e.g., by the pandemic), the inhibitors of compassion are likely to operate across the three flows, whereas the capacity to be compassionate to others and to receive compassion from others may have specifically been affected by fears of contraction and lockdown measures.

A second aim of this study was to consider the impact of perceived threat of COVID-19 on social safeness, as well as the moderating role of compassion. Previous research found that social connectedness can buffer against the negative physical and mental health impact of the coronavirus pandemic, and promote resilience (Nitschke et al., 2020; Palgi et al., 2020; Saltzman et al., 2020); however, the effect perceived threat of COVID-19 might have on one's sense of social safeness has not been explored to date. We hypothesized that perceived threat of COVID-19 would have a negative relationship with social safeness, and this hypothesis was supported by our findings. So, being afraid of contracting SARS-CoV-2 was related to feeling less socially safe and connected to others. Furthermore, given that compassion is a motivation and competency which evolved from mammalian caring and is highly associated with social safeness (Akin \& Akin, 2015; Kelly \& Dupasquier, 2016), it was hypothesized that compassion would act as a protective factor between perceived threat of COVID-19 and social safeness. This hypothesis was partially supported. Self-compassion was significantly associated with social safeness but did not moderate the impact of fear or likelihood of contracting COVID-19 on social safeness. That is, individuals who were able to be compassionate towards themselves in the early 
stages of the pandemic felt more socially safe and connected to others in the context of the pandemic, but this ability to be self-compassionate did not mitigate the negative impact that the threat of contracting the virus had on their experiences of social safeness. It is possible that, given the nature of the threat of the COVID-19 pandemic, with its associated social restrictions and where others might also represent threats (virus carriers), and appear threatening (face masks), being compassionate towards oneself isn't sufficient to mitigate the effect of the threat of the virus on feeling socially safe. In fact, our findings are in line with a prior related study exploring fears of compassion in the context of threat of COVID-19, which found that fears of self-compassion significantly predicted diminished social safeness in the context of COVID-19, but did not moderate the impact of perceived threat of COVID-19 on social safeness (Matos et al., 2021).

However, in line with our hypothesis, receiving compassion from others did emerge as a significant moderator, buffering the negative impact of fear of contracting COVID19 on social safeness and connectedness to others. Thus, individuals who reported receiving more compassion from other people have higher feelings of social safeness and connection to others and these remained high regardless of their fear of COVID-19. Conversely, if individuals were less able to access compassion from others, then the more they perceived COVID-19 as threatening the less socially safe they would feel. This buffering effect was consistent across all 21 countries and again was not affected by individual differences between countries. These findings are supported by the same previous study where, although the three flows of fears of compassion were significant predictors of social safeness, only fears of receiving compassion from others moderated the impact of perceived threat of COVID-19 on feelings of social safeness (Matos et al., 2021). Our results are thus in line with extensive literature concerning the importance of having access to caring relationships and receiving compassion from others in regulating affective processes, physiological states and producing greater wellbeing and a sense of feeling connected to others and socially safe in the world (Brown \& Brown, 2017; Cacioppo et al., 2008; Gilbert, 2020).

Contrarily to our initial hypothesis, compassion for others was not significantly associated with social safeness and did not emerge as a significant moderator on the association between perceived threat of COVID-19 and social safeness. It is possible that in the pandemic there would have been fewer opportunities to express compassion for others and previous research has indeed found that compassion for others has not been strongly associated with psychosocial variables (Kirby et al., 2019).

Given that self-compassion seems to buffer the potential effects of perceived threat of COVID-19 on psychological distress and given the ability of compassion from others to support social safeness in the context of fears of COVID19 , it would seem that compassion-based interventions and dissemination of compassionate strategies of public communication could be implemented to protect against mental health difficulties during and following the pandemic. Individual and group compassion-based interventions, in particular CFT (for patients) or CMT (for public) (Gilbert, 2014, 2020), cultivate compassion across the three flows including self-compassion and receiving compassion from others, and are widely evidenced to reduce psychological distress in a range of conditions and populations (Craig et al., 2020; Kirby et al., 2017; Leaviss \& Uttley, 2015, for reviews). Therefore, providing greater access to individual and/or group CFT and CMT, including via Telehealth, might be pertinent. In fact, in the specific context of the pandemic, an online compassion-focused intervention was found to reduce depression, anxiety, and stress in patients at high risk of psychosis (Cheli et al., 2020). Moreover, graded online compassion-focused interventions, including psycho-education and information sharing, guided practices and strategies, and behavioral applications could be offered more widely to benefit public mental health. Social safeness and receiving compassion might have been affected by lockdown and social distancing procedures, it is therefore important to consider how compassion interventions may be helpful despite lockdown procedures. Online interventions, particularly interactive interventions with opportunities for group or partner work, could offer a good solution to delivering interventions during lockdown procedures. In addition, activities could place emphasis on social acceptance of (shared) suffering as part of the human condition, or cultivating a sense of compassion for others in the absence of direct contact (e.g., with imagery and visualization exercises). Given the evidence indicating that psychological interventions that reliably reduce anxiety and depression may boost immune responses to vaccines (Madison et al., 2021; Vedhara et al., 2019), compassionbased interventions such as CMT/CFT may be worthy of further investigation as possible adjuvants to the SARSCoV-2 vaccine.

In addition, and while not the focus of the current study, given the acute experiences of threat and trauma reported by COVID-19 survivors (e.g., Tingey et al., 2020; Tu et al., 2021) and the damaging lasting effects of the disease on their mental health (e.g., depression, anxiety, post-traumatic stress; Liu et al., 2021; Taquet et al., 2021), it might be relevant to consider the value of compassion-based interventions for these individuals to prevent and address their mental health difficulties and promote their psychosocial wellbeing. In fact, mounting research has supported the positive effects of compassion-focused interventions for people with chronic or physical illness (e.g., Carvalho et al., 2021; Gooding et al., 2020). 
The implementation of community-based strategies to support resilience during the COVID-19 pandemic is an important goal (Serafini et al., 2020). The current findings highlight that self-compassion and compassion from others may mitigate the psychological impact of the ongoing and long-term threat induced by the COVID-19 pandemic. Knowledge accumulated in recent research, coupled with the current study, needs to be integrated by authorities and policy makers who should rapidly adopt compassionate focused strategies, such as compassionate social marketing and public health communications, to reduce the mental health consequences of this pandemic. One such example is the Campaign to End Loneliness BeMoreUs movement in the UK (https://bemoreus.org.uk/). This movement used billboards and a website prompting ideas for how to pay more attention to and connect with others (e.g., phone a friend, talk with a stranger, volunteer in the community). Compassion-focused interventions and strategies should particularly focus on cultivating compassion towards oneself and openness to receiving compassion from others, perhaps by developing abilities to be sensitive to and tolerant of distress in oneself, and competencies to compassionate action to prevent or alleviate it, as well as being receptive to care, support, and help from others.

\section{Limitations and Future Directions}

Differences across the 21 countries in terms of rates of COVID-19 and the timing of peaks of infection and associated lockdown measures may have affected variables such as the perceived threat of COVID-19 and the amount of participants' social contact. Additionally, previous studies have reported cross-cultural differences in the compassion flows (e.g., Steindl et al., 2020) and it is possible that the type of strategies implemented by different countries to limit the spread of the virus (e.g., hard vs mild lockdown) in the early stages of the pandemic might have influenced the interplay between compassion flows, threat of COVID19, and psychosocial distress. Nevertheless, a key strength of the current study was the multivariate multilevel methodology used and the consistency of the predictive and moderator effects across all 21 countries, which were not dominated by individual differences between countries in the levels of the compassion flows, perceived threat of COVID-19, mental health symptoms, and social safeness, thus supporting the universality of compassion as a protective factor against mental health problems and lack of social safeness. Another limitation is that the study did not have representation from all continents. Researchers from Africa were invited but were unable to participate. Future studies should more rigorously pursue participation from less represented continents and regions. This study had an unequal gender distribution, with more female respondents. Even though no gender differences have been reported in the CEAS self-compassion and compassion from others scales, women were found to score higher than men in compassion for others (Gilbert et al., 2017). Thus, in the future research should attempt to recruit more men. Additionally, mounting research has established that many individuals can develop fears, blocks, and resistances to compassion (for self, for others, and from others) and that these increase vulnerability to mental health problems (Gilbert et al., 2011; Kirby et al., 2019 for a review). Hence, given the current findings, future studies could investigate the role of fears of compassion as potential magnifying factors of the impact of perceived threat of COVID-19 on mental health and social safeness. Finally, the cross-sectional nature of the study prevents the establishment of causality. This study is part of a broader project that is collecting longitudinal data and aims to prospectively investigate the buffering effects of compassion throughout the pandemic. Another way to establish causality would be to evaluate the effects of a compassionfocused intervention on decreasing psychological distress, and/or increasing social safeness.

In conclusion, this study provides evidence for the universal protective effects of compassion, in particular selfcompassion and compassion from others, against the harmful effects of the COVID-19 pandemic on mental health and reduced social safeness. Given the damaging effects of the COVID-19 crisis on mental well-being (e.g., Gloster et al., 2020) and the anticipated second-wave mental health pandemic (Prout et al., 2020), the promotion of mental health should constitute a public health priority. Compassionfocused interventions and communications should be prioritized by public health policy makers and providers to promote resilience and address mental health problems during and following the pandemic.

Supplementary Information The online version contains supplementary material available at https://doi.org/10.1007/s12671-021-01822-2.

Acknowledgements The authors would like to thank the Compassionate Mind Foundation for their support in the implementation of the project. We would also like to thank the Tages Onlus for the scientific and organizational support and Giselle Kraus, in the Italian and Canadian arms of this study respectively.

Author Contribution MM, KM, SS, DR, and PG were responsible for the conceptualization and methodology of the study. All authors contributed to the investigation, to the development of resources and materials used in the current study, and to the data collection in their respective countries. MK and $\mathrm{JH}$ were responsible for software, data curation, and formal analysis. MM, KM, MK, JH, SS, NF, ML, and PG wrote the original draft of the manuscript and collaborated with the review and editing of the final draft. All authors approved the final version of the manuscript. MM, MK, JH, PL-S, and AK were responsible for the funding acquisition that supported the current study. This study was supervised and coordinated by MM. 
Funding The overall research received no specific grant from any funding agency, commercial or not-for-profit sectors. This work was supported by the Center for Research in Neuropsychology and Cognitive Behavioral Intervention (CINEICC) funded by the Portuguese Foundation for Science and Technology (M.M., Strategic Project UID/ PSI/00730/2020). The Slovak arm of this study was supported by the Slovak Research and Development Agency (J.H. \& M.K.; Contract no. PP-COVID-20-0074) and the Vedecká grantová agentúra VEGA (J.H.; Grant 1/0075/19). The Canadian arm of the study was supported by the Social Sciences and Humanities Research Council Insight Grant (A.K., ref. 435-2017-0062). The Brazilian arm was supported by the Portuguese Foundation for Science and Technology (P.L.-S.; SFRH/ BD/130677/2017) and the Brazilian National Council for Scientific and Technological Development (M.S.O.; Scientific Productivity Grant).

Data Availability Data cannot be shared publicly because it is part of an ongoing longitudinal study. Data are available from the University of Coimbra Institutional Data Access (contact via cineicc@fpce.uc.pt) for researchers who meet the criteria for access to confidential data after the completion of the longitudinal study.

\section{Declarations}

Ethical Approval The authors declare that all procedures contributing to this work comply with the ethical standards of the relevant national and institutional committees on human experimentation and with the Helsinki Declaration of 1975 and its later amendments. The Ethics Committee of the Faculty of Psychology and Educational Sciences of the University of Coimbra approved the study (CEDI22.04.2020).

Informed Consent Informed consent was obtained from all individual participants included in the study.

Conflict of Interest The authors declare no competing interests.

\section{References}

Ahorsu, D. K., Lin, C.-Y., Imani, V., Saffari, M., Griffiths, M. D., \& Pakpour, A. H. (2020). The fear of COVID-19 scale: Development and initial validation. International Journal of Mental Health and Addiction. https://doi.org/10.1007/ s11469-020-00270-8

Akin, A., \& Akin, U. (2015). Self-compassion as a predictor of social safeness in Turkish university students. Revista Latinoamericana De Psicología, 47(1), 43-49.

Al van Tilburg, M., Edlynn, E., Maddaloni, M., van Kempen, K., Díaz-González de Ferris, M., \& Thomas, J. (2020). High levels of stress due to the SARS-Cov-2 pandemic among parents of children with and without chronic conditions across the USA. Children (Basel, Switzerland), 7(10), 193. https://doi.org/10. 3390/children7100193

Armstrong, B. F., Nitschke, J. P., Bilash, U., \& Zuroff, D. C. (2020). An affect in its own right: Investigating the relationship of social safeness with positive and negative affect. Personality and Individual Differences. https://doi.org/10.1016/j.paid.2019.109670

Barnier, J., Briatte, F., \& Larmarange, J. (2017). Functions to make surveys processing easier. package 'questionr', version 0.6.2. Retrieved from: https://juba.github.io/questionr/

Barton, K. (2015) Package 'MuMIn'. Model selection and model averaging based on information criteria. $\mathrm{R}$ package version 1.15.11
Bates, D., Maechler, M., Bolker, B., \& Walker, S. (2015). Fitting linear mixed-effects models using lme4. Journal of Statistical Software, 67(1), 1-48.

Bitan, D. T., Grossman-Giron, A., Bloch, Y., Mayer, Y., Shiffman, N., \& Mendlovic, S. (2020). Fear of COVID-19 scale: Psychometric characteristics, reliability and validity in the Israeli population. Psychiatry Research, 289, 113100. https://doi.org/10.1016/j. psychres.2020.113100

Blackie, R. A., \& Kocovski, N. L. (2019). Trait self-compassion as a buffer against post-event processing following performance feedback. Mindfulness, 10, 923-932. https://doi.org/10.1007/ s12671-018-1052-7

Brown, S. L., \& Brown, R. M. (2017). Compassionate neurobiology and health. In E. M. Seppälä, E. Simon-Thomas, S. L. Brown, M. C. Worline, C. D. Cameron, \& J. R. Doty (Eds.), The Oxford Handbook of Compassion Science (pp. 159-172). Oxford University Press.

Cacioppo, J. T., \& Patrick, W. (2008). Loneliness. Norton.

Carter, C. S. (2014). Oxytocin pathways and the evolution of human behavior. Annual Review of Psychology, 65, 17-39. https://doi. org/10.1146/annurev-psych-010213-115110

Carter, S., Bartal, I. B., \& Porges, E. (2017). The roots of compassion: An evolutionary and neurobiological perspective. In E. M. Seppälä, E. Simon-Thomas, S. L. Brown, M. C. Worline, C. D. Cameron, \& J. R. Doty (Eds.), The Oxford Handbook of Compassion Science (pp. 173-188). Oxford University Press.

Carvalho, S. A., Skvarc, D., Barbosa, R., Tavares, T., Santos, D., \& Trindade, I. A. (2021). A pilot randomized controlled trial of online acceptance and commitment therapy versus compassionfocused therapy for chronic illness. Clinical Psychology \& Psychotherapy. https://doi.org/10.1002/cpp.2643

Cheli, S., Cavalletti, V., \& Petrocchi, N. (2020). An online compassionfocused crisis intervention during COVID-19 lockdown: A cases series on patients at high risk for psychosis. Psychosis. https:// doi.org/10.1080/17522439.2020.1786148

Cohen, S. (2021). Psychosocial vulnerabilities to upper respiratory infectious illness: Implications for susceptibility to coronavirus disease 2019 (COVID-19). Perspectives on Psychological Science, 16(1), 161-174. https://doi.org/10.1177/1745691620 942516

Cozolino, L. (2007). The neuroscience of human relationships: Attachment and the developing brain. Norton.

Craig, C., Hiskey, S., \& Spector, A. (2020). Compassion focused therapy: A systematic review of its effectiveness and acceptability in clinical populations. Expert Review Neurotherapeutics, 385-400, 1746184. https://doi.org/10.1080/14737175.2020.1746184

Crocker, J., \& Canevello, A. (2012). Consequences of self-image and compassionate goals. In P. G. Devine \& A. Plant (Eds.), Advances in experimental social psychology (pp. 229-277). Elsevier.

Dunbar, R. I. M. (2016b). The social brain hypothesis and human evolution. Oxford Research Encyclopedia of Psychology. https://doi. org/10.1093/acrefore/9780190236557.013.44

Dunbar, R. I. M. (2016). The social brain hypothesis and human evolution. In Oxford Research Encyclopedia of Psychology (pp. 1-33). Oxford University Press. https://doi.org/10.1093/ acrefore/9780190236557.013.44

Edwards, L. J., Muller, K. E., Wolfinger, R. D., Qaqish, B. F., \& Schabenberger, O. (2008). An R2 statistic for fixed effects in the linear mixed model. Statistics in Medicine, 27(29), 6137-6157. https://doi.org/10.1002/sim.3429

Ferreira, C., Barreto, M., \& Oliveira, S. (2021). The link between major life events and quality of life: The role of compassionate abilities. Community Mental Health Journal, 57, 219-227. https://doi.org/ 10.1007/s10597-020-00638-z

Fitzpatrick, K. M., Harris, C., \& Drawve, G. (2020). Fear of COVID-19 and the mental health consequences in America. Psychological 
Trauma: Theory, Research, Practice, and Policy, 12, S17-S21. https://doi.org/10.1037/tra0000924

Fredrickson, B. L., Grewen, K. M., Coffey, K. A., Algoe, S. B., Firestine, A. M., Arevalo, J., Ma, J., \& Cole, S. W. (2013). A functional genomic perspective on human well-being. Proceedings of the National Academy of Sciences of the United States of America, 110(33), 13684-13689. https://doi.org/10.1073/pnas. 1305419110

Gilbert, P. (2009). The compassionate mind: A new approach to the challenge of life. Constable \& Robinson.

Gilbert, P. (2014). The origins and nature of compassion focused therapy. British Journal of Clinical Psychology, 53, 6-41. https://doi. org/10.1111/bjc. 12043

Gilbert, P. (2019). Explorations into the nature and function of compassion. Current Opinion in Psychology, 28, 108-114. https://doi. org/10.1016/j.copsyc.2018.12.002

Gilbert, P. (2020). Compassion: From its evolution to a psychotherapy. Frontiers in Psychology, 11, 3123. https://doi.org/10.3389/fpsyg. 2020.586161

Gilbert, P., \& Procter, S. (2006). Compassionate mind training for people with high shame and self-criticism: Overview and pilot study of a group therapy approach. Clinical Psychology and Psychotherapy, 13, 351-379. https://doi.org/10.1002/cpp.507

Gilbert, P., McEwan, K., Mitra, R., Franks, L., Richter, A., \& Rockliff, H. (2008). Feeling safe and content: A specific affect regulation system? Relationship to depression, anxiety, stress, and selfcriticism. The Journal of Positive Psychology, 3(3), 182-191. https://doi.org/10.1080/17439760801999461

Gilbert, P., McEwan, K., Matos, M., \& Rivis, A. (2011). Fears of compassion: Development of three self-report measures. Psychology and Psychotherapy: Theory, Research and Practice, 84, 239-255. https://doi.org/10.1348/147608310X526511

Gilbert, P., Catarino, F., Duarte, C., Matos, M., Kolts, R., Stubbs, J., Ceresatto, L., Duarte, J., Pinto-Gouveia, J., \& Basran, J. (2017). The development of compassionate engagement and action scales for self and others. Journal of Compassionate Health Care, 4(1), 1-24. https://doi.org/10.1186/s40639-017-0033-3

Gloster, A. T., Lamnisos, D., Lubenko, J., Presti, G., Squatrito, V., Constantinou, M., Nicolaou, C., Papacostas, S., Aydın, G., Chong, Y. Y., Chien, W. T., Cheng, H. Y., Ruiz, F. J., Garcia-Martin, M. B., Obando-Posada, D. P., Segura-Vargas, M. A., Vasiliou, V. S., McHugh, L., ..., Karekla, M. (2020). Impact of COVID-19 pandemic on mental health: An international study. PLoS ONE, 15(12), e0244809. https://doi.org/10.1371/journal.pone.0244809

Gooding, H., Stedmon, J., \& Crix, D. (2020). 'All these things don't take the pain away but they do help you to accept it': Making the case for compassion-focused therapy in the management of persistent pain. British Journal of Pain, 14(1), 31-41. https://doi. org/10.1177/2049463719857099

Green, P., MacLeod, C. J., \& Alday, P. (2016). Package 'simr'.

Heath, P. J., Brenner, R. E., Lannin, D. G., \& Vogel, D. L. (2018). Self-compassion moderates the relationship of perceived public and anticipated self-stigma of seeking help. Stigma and Health, 3, 65-68. https://doi.org/10.1037/sah0000072

Hermanto, N., Zuroff, D. C., Kopala-Sibley, D. C., Kelly, A. C., Matos, M., \& Gilbert, P. (2016). Ability to receive compassion from others buffers the depressogenic effect of self-criticism: A crosscultural multi-study analysis. Personality and Individual Differences, 98, 324-332. https://doi.org/10.1016/j.paid.2016.04.055

Holmes, E. A., O'Connor, R. C., Perry, V. H., Tracey, I., Wessely, S., Arseneault, L., Ballard, C., Christensen, H., Silver, R. C., Everall, I., Ford, T., John, A., Kabir, T., King, K., Madan, I., Michie, S., Przybylski, A. K., Shafran, R., Sweeney, A., ..., Bullmore, E. (2020). Multidisciplinary research priorities for the COVID-19 pandemic: A call for action for mental health science. The Lancet Psychiatry, 547-560, 30168. https://doi. org/10.1016/S2215-0366(20)30168-1

Hox, J. J., Moerbeek, M., \& Van de Schoot, R. (2017). Multilevel analysis: Techniques and applications (3rd ed.). Routledge.

Irons, C., \& Heriot-Maitland, C. (2020). Compassionate Mind Training: An 8-week group for the general public. Theory, Research and Practice. Advance online publication. https://doi.org/10. 1111/papt. 12320

Jaeger, B. C., Edwards, L. J., Das, K., \& Sen, P. K. (2016). An R2 statistic for fixed effects in the generalized linear mixed model. Journal of Applied Statistics, 44(6), 1086-1105.

Jiménez, O., Sánchez-Sánchez, L. C., \& García-Montes, J. M. (2020). Psychological impact of COVID-19 confinement and its relationship with meditation. International Journal of Environmental Research and Public Health, 17, 6642. https://doi. org/10.1080/02664763.2016.1193725

Kanovsky, M., \& Halamová, J. (2020). Perceived threat of the coronavirus and the role of trust in safeguards: A case study in Slovakia. Frontiers in Psychology, 11, 554160. https://doi.org/ 10.3389/fpsyg.2020.554160

Kavaklı, M., Ak, M., Uğuz, F., \& Türkmen, O. O. (2020). The mediating role of self-compassion in the relationship between perceived COVID-19 threat and death anxiety. Turkish Journal Od Clinical Psychiatry, 23, 15-23. https://doi.org/10.5505/ kpd.2020.59862

Kelly, A. C., \& Dupasquier, J. (2016). Social safeness mediates the relationship between recalled parental warmth and the capacity for self-compassion and receiving compassion. Personality and Individual Differences, 89, 157-161. https://doi.org/10.1016/j. paid.2015.10.017

Kelly, A. C., Zuroff, D. C., Leybman, M. J., \& Gilbert, P. (2012). Social safeness, received social support, and maladjustment: Testing a tripartite model of affect regulation. Cognitive Therapy and Research, 36(6), 815-826. https://doi.org/10.1007/ s10608-011-9432-5

Kim, J. J., Parker, S. L., Doty, J. R., Cunnington, R., Gilbert, P., \& Kirby, J. N. (2020). Neurophysiological and behavioural markers of compassion. Scientific Reports, 10(1), 1-9. https://doi.org/10. 1038/s41598-020-63846-3

Kirby, J. N., Tellegen, C. L., \& Steindl, S. R. (2017). A meta-analysis of compassion-based interventions: Current state of knowledge and future directions. Behavior Therapy, 48(6), 778-792. https:// doi.org/10.1016/j.beth.2017.06.003

Kirby, J. N., Day, J., \& Sagar, V. (2019). The 'Flow' of compassion: A meta-analysis of the fears of compassion scales and psychological functioning. Clinical Psychology Review, 70, 26-39. https:// doi.org/10.1016/j.cpr.2019.03.001

Kirby., J. \& Gilbert, P. (2017). The emergence of the compassion focused therapies. In P. Gilbert (Ed.), Compassion: Concepts, Research and Applications (pp. 258-285). Routledge.

Klimecki, O. M., Leiberg, S., Ricard, M., \& Singer, T. (2014). Differential pattern of functional brain plasticity after compassion and empathy training. SOcial Cognitive and Affective Neuroscience, 9(6), 873-879. https://doi.org/10.1093/scan/nst060

LaHuis, D. M., Hartman, M. J., Hakoyama, S., \& Clark, P. C. (2014). Explained variance measures for multilevel models. Organizational Research Methods, 17(4), 433-451. https://doi.org/10. 1177/1094428114541701

Lau, B.H.-P., Chan, C.L.-W., \& Ng, S.-M. (2020). Self-compassion buffers the adverse mental health impacts of COVID-19-related threats: Results from a cross-sectional survey at the first peak of Hong Kong's outbreak. Frontiers in Psychiatry, 11, 585270. https://doi.org/10.3389/fpsyt.2020.585270

Leaviss, J., \& Uttley, L. (2015). Psychotherapeutic benefits of compassion-focused therapy: An early systematic review. Psychological 
Medicine, 45, 927-945. https://doi.org/10.1017/S003329171 4002141

Lee, C. M., Cadigan, J. M., \& Rhew, I. C. (2020). Increases in loneliness among young adults during the COVID-19 pandemic and association with increases in mental health problems. The Journal of Adolescent Health: Official Publication of the Society for Adolescent Medicine, 67(5), 714-717. https://doi.org/10.1016/j. jadohealth.2020.08.009

Li, A., Wang, S., Cai, M., Sun, R., \& Liu, X. (2021). Self-compassion and life-satisfaction among Chinese self-quarantined residents during COVID-19 pandemic: A moderated mediation model of positive coping and gender. Personality and Individual Differences, 170, 110457. https://doi.org/10.1016/j.paid.2020.110457

Lindsey, S. (2017). Examining the psychometric properties of the compassionate engagement and action scales in the general population. University of Essex.

Liu, D., Baumeister, R. F., \& Zhou, Y. (2021). Mental health outcomes of coronavirus infection survivors: A rapid meta-analysis. Journal of Psychiatric Research, 137, 542-553. https://doi.org/10. 1016/j.jpsychires.2020.10.015

Lopez, A., Sanderman, R., Ranchor, A. V., \& Schroevers, M. J. (2018). Compassion for others and self-compassion: Levels, correlates, and relationship with psychological well-being. Mindfulness, 9, 325-331. https://doi.org/10.1007/s12671-017-0777-z

Lovibond, S. H., \& Lovibond, P. F. (1995). Manual for the Depression Anxiety Stress Scales (2nd ed.). Psychology Foundation.

Lüdecke, D. (2018). sjPlot: Data visualization for statistics in social science. (R package version 2.6.1). Retrieved from https://CRAN.Rproject.org/package $=$ sjPlot

Luo, X., Qiao, L., \& Che, X. (2018). Self-compassion modulates heart rate variability and negative affect to experimentally induced stress. Mindfulness, 9, 1522-1528. https://doi.org/10.1007/ s12671-018-0900-9

MacBeth, A., \& Gumley, A. (2012). Exploring compassion: A metaanalysis of the association between self-compassion and psychopathology. Clinical Psychology Review, 32, 545-552. https://doi. org/10.1016/j.cpr.2012.06.003

Madison, A. A., Shrout, M. R., Renna, M. E., \& Kiecolt-Glaser, J. K. (2021). Psychological and behavioral predictors of vaccine efficacy: Considerations for COVID-19. Perspectives on Psychological Science. https://doi.org/10.1177/1745691621989243

Mascaro, J. S., Florian, M. P., Ash, M. J., Palmer, P. K., Frazier, T., Condon, P., \& Raison, C. (2020). Ways of knowing compassion: How do we come to know, understand, and measure compassion when we see it? Frontiers in Psychology, 11, 547241. https://doi. org/10.3389/fpsyg.2020.547241

Matos, M., Duarte, C., \& Pinto-Gouveia, J. (2015). Constructing a self protected against shame: The importance of warmth and safeness memories and feelings on the association between shame memories and depression. International Journal of Psychology and Psychological Therapy, 15, 317-335.

Matos, M., Duarte, C., Duarte, J., Pinto-Gouveia, J., Petrocchi, N., Basran, J., \& Gilbert, P. (2017). Psychological and physiological effects of compassionate mind training: A pilot randomized controlled study. Mindfulness, 8(6), 1699-1712. https://doi.org/ 10.1007/s12671-017-0745-7

Matos, M., McEwan, K., Kanovský, M., Halamová, J., Steindl, S., Ferreira, N., Linharelhos, M., Rijo, D., Asano, K., Gregório, S., Márquez, M., Vilas, S., Brito-Pons, G., Lucena-Santos, P., Oliveira, M., Souza, E., Llobenes, L., Gumiy, N., Costa, M., ..., Gilbert, P. (2021). Fears of compassion magnify the harmful effects of threat of COVID-19 on mental health and social safeness across 21 countries. Clinical Psychology \& Psychotherapy. https://doi.org/10.1002/cpp.2601

Mayseless, O. (2016). The caring motivation: An integrated theory. Oxford University Press.
Miller, J. G., Kahle, S., Lopez, M., \& Hastings, P. D. (2015). Compassionate love buffers stress-reactive mothers from fight-or-flight parenting. Developmental Psychology, 51(1), 36-43. https://doi. org/10.1037/a0038236

Muris, P., \& Petrocchi, N. (2017). Protection or vulnerability? A meta-analysis of the relations between the positive and negative components of self-compassion and psychopathology. Clinical Psychology and Psychotherapy, 24, 373-383. https://doi.org/10. 1002/cpp.2005

Murphy, D., Williamson, C., Baumann, J., Busuttil, W., \& Fear, N. T. (2020). Exploring the impact of COVID-19 and restrictions to daily living as a result of social distancing within veterans with pre-existing mental health difficulties. BMJ military health, bmjmilitary-2020-001622. https://doi.org/10.1136/bmjmi litary-2020-001622

Nakagawa, S., \& Schielzeth, H. (2013). A general and simple method for obtaining R2 from generalized linear mixed-effects models. Methods in Ecology and Evolution, 4(2), 133-142. https://doi. org/10.1111/j.2041-210x.2012.00261.x

Napper, L. E., Fisher, D. G., \& Reynolds, G. L. (2012). Development of the perceived risk of HIV scale. AIDS and Behavior, 16, 10751083. https://doi.org/10.1007/s10461-011-0003-2

Neff, K. D. (2003). Development and validation of a scale to measure self-compassion. Self and Identity, 2, 223-250. https://doi.org/ 10.1080/15298860390209035

Nitschke, J. P., Forbes, P. A., Ali, N., Cutler, J., Apps, M. A., Lockwood, P. L., \& Lamm, C. (2020). Resilience during uncertainty? Greater social connectedness during COVID-19 lockdown is associated with reduced distress and fatigue. British Journal of Health Psychology. https://doi.org/10.1111/bjhp.12485

Oliveira, S., Trindade, I. A., \& Ferreira, C. (2018). The buffer effect of body compassion on the association between shame and body and eating difficulties. Appetite, 125, 118-123. https://doi.org/10. 1016/j.appet.2018.01.031

Palgi, Y., Shrira, A., Ring, L., Bodner, E., Avidor, S., Bergman, Y., Cohen-Fridel, S., Keisari, S., \& Hoffman, Y. (2020). The loneliness pandemic: Loneliness and other concomitants of depression, anxiety and their comorbidity during the COVID-19 outbreak. Journal of Affective Disorders, 275, 109-111. https://doi.org/10. 1016/j.jad.2020.06.036

Porges, S. W. (2007). The polyvagal perspective. Biological Psychology, 74, 116-143. https://doi.org/10.1016/j.biopsycho.2006.06. 009

Porges, S. W. (2017). Vagal pathways: portals to compassion i. In E. M. Seppälä, E. Simon-Thomas, S. L. Brown, M. C. Worline, C. D. Cameron, \& J. R. Doty (Eds.), The Oxford Handbook of Compassion Science (pp. 189-202). Oxford University Press.

Prout, T. A., Zilcha-Mano, S., Aafjes-van Doorn, K., Békés, V., Christman-Cohen, I., Whistler, K., Kui, T., \& Di Giuseppe, M. (2020). Identifying predictors of psychological distress during COVID19: A machine learning approach. Frontiers in Psychology, 11, 586202. https://doi.org/10.3389/fpsyg.2020.586202

R Core Team (2020). R: A language and environment for statistical computing. R Foundation for Statistical Computing, Vienna, Austria. Retrieved 15th January 2021 from http:/ /www.R-proje ct.org/.

Ricard, M. (2015). Altruism: The power of compassion to change itself and the world. Atlantic Books.

Saltzman, L. Y., Hansel, T. C., \& Bordnick, P. S. (2020). Loneliness, isolation, and social support factors in post-COVID-19 mental health. Psychological Trauma: Theory, Research, Practice, and Policy, 12, S55-S57. https://doi.org/10.1037/tra0000703

Schnepper, R., Reichenberger, J., \& Blechert, J. (2020). Being my own companion in times of social isolation - A 14-day mobile self-compassion intervention improves stress levels and Eating 
Behavior. Frontiers in Psychology, 11, 595806. https://doi.org/ 10.3389/fpsyg.2020.595806

Seppälä, E. M., Simon-Thomas, E., Brown, S. L., Worline, M. C., Cameron, C. D., \& Doty, J. R. (Eds.). (2017). The Oxford handbook of compassion science. Oxford University Press.

Serafini, G., Parmigiani, B., Amerio, A., Aguglia, A., Sher, L., \& Amore, M. (2020). The psychological impact of COVID-19 on the mental health in the general population. QJM: An International Journal of Medicine, 113(8), 531-537. https://doi.org/10. 1093/qjmed/hcaa201

Snijders, T. A. B., \& Bosker, R. J. (2012). Multilevel analysis: An introduction to basic and advanced multilevel modelling (2nd ed.). Sage.

Steindl, S., Matos, M., \& Creed, A. (2018). Early shame and safeness memories, and later depressive symptoms and safe affect: The mediating role of self-compassion. Current Psychology, 40(2), 761-771. https://doi.org/10.1007/s12144-018-9990-8

Steindl, S., Yiu, R., Bauman, T., \& Matos, M. (2020). Comparing compassion across cultures: Similarities and differences among Australians and Singaporeans. Australian Psychologist, 55(3), 208-219. https://doi.org/10.1111/ap.12433.

Taquet, M., Geddes, J. R., Husain, M., Luciano, S., \& Harrison, P. J. (2021). 6-month neurological and psychiatric outcomes in 236 379 survivors of COVID-19: A retrospective cohort study using electronic health records. The Lancet Psychiatry, 8(5), 416-427. https://doi.org/10.1016/S2215-0366(21)00084-5

Tingey, J. L., Bentley, J. A., \& Hosey, M. M. (2020). COVID-19: Understanding and mitigating trauma in ICU survivors. Psychological Trauma: Theory, Research, Practice, and Policy, 12(S1), S100. https://doi.org/10.1037/tra0000884

Tu, Y., Zhang, Y., Li, Y., Zhao, Q., Bi, Y., Lu, X., Kong, Y., Wang, L., Lu, Z., \& Hu, L. (2021). Post-traumatic stress symptoms in COVID-19 survivors: A self-report and brain imaging follow-up study. Molecular Psychiatry, 1-6. Advance online publication. https://doi.org/10.1038/s41380-021-01223-w

Vedhara, K., Ayling, K., Sunger, K., Caldwell, D. M., Halliday, V., Fairclough, L., Avery, A., Robles, L., Garibaldi, J., Welton, N. J., \& Royal, S. (2019). Psychological interventions as vaccine adjuvants: A systematic review. Vaccine, 37(25), 3255-3266. https://doi.org/10.1016/j.vaccine.2019.04.091

Vinkers, C. H., van Amelsvoort, T., Bisson, J. I., Branchi, I., Cryan, J. F., Domschke, K., Howes, O. D., Manchia, M., Pinto, L., de Quervain, D., Schmidt, M. V., \& van der Wee, N. (2020). Stress resilience during the coronavirus pandemic. European $\mathrm{Neu}$ ropsychopharmacology: The Journal of the European College of Neuropsychopharmacology, 35, 12-16. https://doi.org/10. 1016/j.euroneuro.2020.05.003
Wang, C., Pan, R., Wan, X., Tan, Y., Xu, L., Ho, C. S., \& Ho, R. C. (2020a). Immediate psychological responses and associated factors during the initial stage of the 2019 coronavirus disease (COVID-19) epidemic among the general population in China. International Journal of Environmental Research and Public Health, 17(5), 1729. https://doi.org/10.3390/ijerph17051729

Wang, S., Zhang, Y., Ding, W., Meng, Y., Hu, H., Liu, Z., Zeng, X., \& Wang, M. (2020b). Psychological distress and sleep problems when people are under interpersonal isolation during an epidemic: A nationwide multicenter cross-sectional study. European Psychiatry: The Journal of the Association of European Psychiatrists, 63(1), e77. https://doi.org/10.1192/j.eurpsy.2020.78

Wong, C. C. Y., Mak, W. W. S., \& Liao, K. Y. (2016). Self-compassion: A potential buffer against affiliate stigma experienced by parents of children with autism spectrum disorders. Mindfulness, 7, 1385-1395. https://doi.org/10.1007/s12671-016-0580-2

Wong, S., Zhang, D., Sit, R., Yip, B., Chung, R. Y., Wong, C., Chan, D., Sun, W., Kwok, K. O., \& Mercer, S. W. (2020). Impact of COVID-19 on loneliness, mental health, and health service utilisation: A prospective cohort study of older adults with multimorbidity in primary care. The British Journal of General Practice: The Journal of the Royal College of General Practitioners, 70(700), e817-e824. https://doi.org/10.3399/bjgp20X713021

World Health Organization (WHO) (2020). Mental health and psychosocial considerations during the COVID-19 outbreak. World Health Organization. Retrieved 20th January 2021 from https:// apps.who.int/iris/bitstream/handle/10665/331490/WHO-2019nCoV-MentalHealth-2020.1-eng.pdf

Worldometer - COVID-19 Coronavirus Pandemic. Retrieved 20th January 2021. Available at: https://www.worldometers.info/ coronavirus/

Yarnell, L. M., \& Neff, K. D. (2013). Self-compassion, interpersonal conflict resolutions, and well-being. Self and Identity, 12(2), 146-159. https://doi.org/10.1080/15298868.2011.649545

Zessin, U., Dickhäuser, O., \& Garbade, S. (2015). The relationship between self-compassion and well-being: A meta-analysis. Applied Psychology, 7, 340-364. https://doi.org/10.1111/aphw. 12051

Publisher's Note Springer Nature remains neutral with regard to jurisdictional claims in published maps and institutional affiliations. 


\section{Authors and Affiliations}

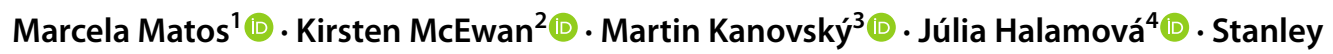

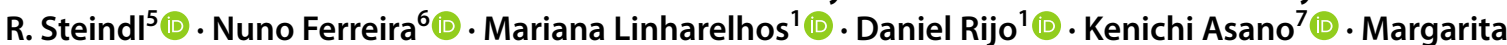

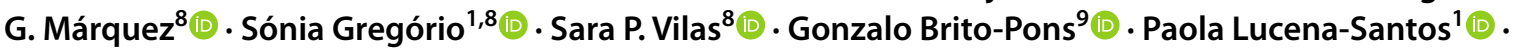
Margareth da Silva Oliveira ${ }^{10}$ - Erika Leonardo de Souza ${ }^{11}$ • Lorena Llobenes $^{12} \cdot$ Natali Gumiy $^{12} \cdot$ Maria $^{13}$ Ileana Costa ${ }^{12}$. Noor Habib ${ }^{13}$. Reham Hakem ${ }^{13}$. Hussain Khrad ${ }^{13}$. Ahmad Alzahrani ${ }^{13}$. Simone Cheli ${ }^{14}$.

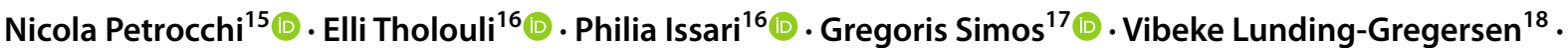

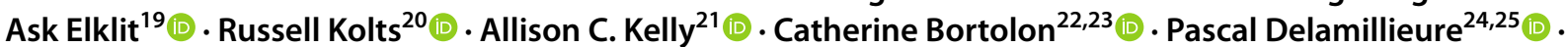

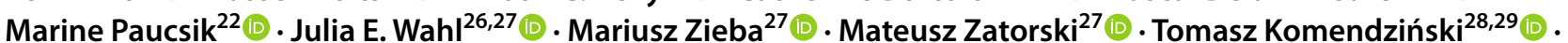

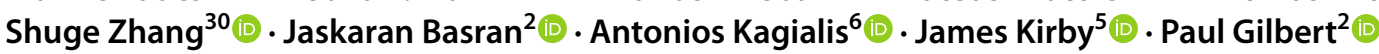

1 Center for Research in Neuropsychology and Cognitive Behavioral Intervention (CINEICC), University of Coimbra, 3000-115 Coimbra, Portugal

2 College of Health, Psychology and Social Care, Centre for Compassion Research and Training, University of Derby, Derby, UK

3 Institute of Social Anthropology, Faculty of Social and Economic Sciences, Comenius University, Bratislava, Slovakia

4 Institute of Applied Psychology, Faculty of Social and Economic Sciences, Comenius University, Bratislava, Slovakia

5 School of Psychology, Compassionate Mind Research Group, University of Queensland, Brisbane, Australia

6 Department of Social Sciences, University of Nicosia, Nicosia, Cyprus

7 Department of Psychological Counseling, Faculty of Psychology, Mejiro University, Tokyo, Japan

8 Department of Psychology, Faculty of Biomedical and Health Sciences. Behavior, emotions, and health research group, Universidad Europea de Madrid, Madrid, Spain

9 Escuela de Psicología, Pontificia Universidad Católica de Chile, Santiago, Chile

10 Evaluation and Treatment in Cognitive and Behavioral Psychotherapies - Research Group (GAAPCC), Pontifical Catholic University of Rio Grande Do Sul, Porto Alegre, Brazil

11 Conectta: Mindfulness \& Compassion, São Paulo, Brazil

12 Motivación Compasiva, Buenos Aires, Argentina

13 Neuroscience Department, Section of Psychiatry and Psychology, King Faisal Specialist Hospital and Research Centre (KFSH\&RC), Jeddah, Saudi Arabia

14 School of Human Health Sciences, University of Florence, Florence, Italy
15 Department of Economics and Social Sciences, John Cabot University, Rome, Italy

16 Center for Qualitative Research in Psychology and Psychosocial Well-Being, National and Kapodistrian University of Athens, Athens, Greece

17 Department of Educational and Social Policy, University of Macedonia, Thessaloniki, Greece

18 Mindwork Psycological Center, Copenhagen, Denmark

19 Department of Psychology, University of Southern Denmark, Odense, Denmark

20 Department of Psychology, Eastern Washington University, Cheney, WA, USA

21 Department of Psychology, University of Waterloo, Waterloo, Canada

22 Laboratoire Inter-Universitaire de Psychologie: Personnalité, Cognition Et Changement Social, Grenoble Alpes University, Grenoble, France

23 C3R - Réhabilitation psychosociale et remédiation cognitive, Centre Hospitalier Alpes Isère, Grenoble, France

24 Service de Psychiatrie Adulte, CHU de Caen, 14000 Caen, France

25 UNICAEN, ISTS, GIP Cyceron, University of Normandy, Caen, France

26 The Mind Institute Poland, Warsaw, Poland

27 SWPS University of Social Sciences and Humanities, Warsaw \&, Poznań, Poland

28 Department of Cognitive Science, Nicolaus Copernicus University, Torún, Poland

29 Neurocognitive Laboratory, Centre for Modern Interdisciplinary Technologies, Nicolaus Copernicus University, Torún, Poland

30 School of Human Sciences, University of Derby, Derby, UK 